\title{
Effects of Water Stress on Colonization of Poplar Stems and Excised Leaf Disks by Septoria musiva
}

\author{
D. L. Maxwell, E. L. Kruger, and G. R. Stanosz
}

First and third authors: Department of Plant Pathology; and second author: Department of Forestry; University of Wisconsin-Madison, 1630 Linden Drive, Madison 53706-1598.

Accepted for publication 14 January 1997.

\begin{abstract}
Maxwell, D. L., Kruger, E. L., and Stanosz, G. R. 1997. Effects of water stress on colonization of poplar stems and excised leaf disks by Septoria musiva. Phytopathology 87:381-388.

Septoria musiva causes leaf spot and canker diseases of trees in the genus Populus, and is one of the most damaging fungal pathogens of hybrid poplar in eastern North America. The effect of host water stress on Septoria canker development was studied in two separate greenhouse experiments. Hybrid poplar clones NM6, NC11396, and NE308 were stressed by withholding water until predawn water potential fell below

(control) to the wound. Cankers on inoculated water-stressed trees were significantly larger than those on nonstressed trees. A leaf disk assay also was conducted three times with the NM6 and NE308 trees. We cut two disks from each of 120 stressed and 120 well-watered trees, placing them on water agar in 24-well tissue culture plates. A conidial suspension was applied to one disk in each pair and sterile water to the other. Inoculated disks from water-stressed trees developed less necrosis than those from well-watered trees. These results demonstrate that environmental influences on host condition must be considered in evaluating resistance of clones proposed for widespread culture of hybrid poplar.
\end{abstract} $-1.0 \mathrm{MPa}$. Stems were treated by removing a leaf and applying agar plugs that were either colonized by S. musiva (inoculated) or sterile
Additional keywords: drought, Mycosphaerella populorum.
The anticipation of shrinking petroleum and forest product supplies is stimulating the development of short-rotation intensive culture of woody plants as an alternative fuel and fiber resource (26). In the United States, research has focused on the use of Populus species for this purpose, because they are among the fastest growing trees in the temperate zone. Many agents, however, limit the ability of poplars to achieve their potential. Among these is the fungus Septoria musiva Peck (teleomorph = Mycosphaerella populorum G.E. Thompson).

S. musiva is found in eastern and central North America, (3) as well as in the Crimea and the Caucasus region of Asia (31). The fungus overwinters in leaf debris, producing ostiolate perithecia in the spring that give rise to airborne ascospores at budbreak (21). Ascospores can penetrate leaves through stomata (20), but little information is available on their role in stem infection. The fungus also produces pycnidia that exude cirrhi containing conidia. Conidia are rain splashed (21) and infect leaves and stems (10).

S. musiva causes leaf spot and canker diseases and is one of the most serious agents of damage to hybrid poplars in the eastern United States and Canada $(3,16,21,32,33)$. Leaf spotting can reduce the photosynthetic area of the tree and can cause premature defoliation (32). Cankers can predispose the tree to wind damage (16) and can girdle the tree (33), killing the portion of the tree above the infection site. McNabb et al. (15) reported biomass losses as high as $63 \%$ in a plantation.

Little information is available about the potential effects of host condition on diseases caused by $S$. musiva. Field trials have been conducted to screen poplar clones for resistance to the fungus, but disease incidence and severity have been observed to vary from site to site $(22,24)$. In a field study, Septoria canker incidence was more severe on a site in which the water table was low (1). How-

Corresponding author: D. L. Maxwell; E-mail address: dlm@plantpath.wisc.edu

Publication no. P-1997-0220-01R

(c) 1997 The American Phytopathological Society ever, other factors including the concentrations of various nutrients and the presence of poplar-and-willow borer (Cryptorhynchus lapthi) also differed, making it difficult to draw definite conclusions. In laboratory inoculations of dormant Populus tremuloides Michx. and P. trichocarpa Torr. \& A. Gray stem cuttings, lower bark moisture was associated with greater colonization of stems by $S$. musiva (4). However, direct experimental information is lacking on the effects of specific environmental variables, including water potential, on canker development by intact, growing plants under controlled conditions.

Our objective was to determine the effect of moisture stress on the colonization of Populus hybrid stems by $S$. musiva. We also evaluated the influence of host moisture stress on the response of inoculated leaf disks in a bioassay that has been used to estimate relative resistance of clones to $S$. musiva. The responses evaluated included canker development in wounded, inoculated shoots and necrosis of excised leaf disks. Three hybrid poplar clones and two isolates of $S$. musiva were used in greenhouse trials.

\section{MATERIALS AND METHODS}

Experiment 1, stem inoculation. We conducted a greenhouse trial using rooted greenwood cuttings of two hybrid poplar clones with differing levels of resistance to $S$. musiva. Single cuttings of NM6 ( $P$. nigra L. $\times P$. maximowiczii Henry), a moderately resistant clone (30), and NC11396 (P. nigra $\times$ P. beroliniensis Dippel), a more susceptible clone, were planted in Fafard mix \#2 (Fafard Inc., Agawam, MA) in paper cartons measuring $7 \times 7 \times 18 \mathrm{~cm}$. Plants were placed in a greenhouse with ambient light supplemented with $16 \mathrm{~h}$ of light from $400-\mathrm{W}$ sodium vapor lamps.

Two different watering regimens were used to create differences in host moisture status. We watered the trees to field capacity either three times per week (nonstressed), or after the soil water potential fell below $-1.0 \mathrm{MPa}$ (stressed). Moisture status was monitored by measuring predawn leaf water potential $\left(\psi_{\mathrm{PD}}\right)$ for one tree per treatment three times per week using a pressure chamber 
(PMS Instruments, Corvallis, OR). If the $\psi_{\mathrm{PD}}$ of any leaf sampled was below $-1.0 \mathrm{MPa}$, we immediately measured leaves from three trees in each treatment. We intensively sampled to allow statistical comparisons of treatment means using the general linear model (proc GLM) in SAS (SAS Institute, Cary, NC). The design was a two-way factorial using Fisher's least significant difference to test for significant differences among treatment means at $\alpha=0.05$.

Four stem treatments were applied on November 1, 1993 (day of year 305): nonwounded control, wounded control, and wounding followed by inoculation with one of two $S$. musiva isolates. We marked the fourth fully expanded leaf on the nonwounded controls. For the other three stem treatments, this leaf was removed to create a fresh leaf scar. To this wound we applied either a sterile 5-mm plug of $S$. musiva on poplar leaf decoction agar (PLDA) (13), or one cut from the margin of a 10-day-old culture on PLDA. The plug was held in a depression in a piece of plastic foam and bound to the stem with Parafilm; foam and Parafilm were removed 7 days later. The cultures were obtained from single-conidium isolates from the same leaf spot, and designated 92-49A and 92-49C. Wounded control and inoculated treatments were randomly assigned to eight or seven trees per combination of watering regimen (stress), and stem treatment (inoculation) for NC11396 and NM6, respectively. The remaining seven NC11396 and six NM6 trees were used as nonwounded controls.

Response of trees was evaluated after 80 days. Canker length was measured, to the nearest millimeter, as the length of either the wound or of the associated discoloration, whichever was larger. Percentage of the stem girdled was visually estimated to the nearest percent. In trees treated with sterile agar plugs, subsequently produced callus tissue was the response evaluated. Because nonwounded controls showed no response, they were omitted from statistical analysis. We used the GLM procedure in SAS to perform a three-way factorial analysis of the data. The full analysis of variance (ANOVA) models for canker length and estimated girdling percentage showed large differences between wounded control and S. musiva inoculated treatments. However, because the wounded control treatment means had much smaller standard deviations, we performed separate analyses to avoid violating the assumption of equal variances.

Experiment 2, stem inoculation. In this experiment, resistant clone NM6 was used again, but clone NE308 (P. nigra var. charkowiensis $\times P$. berolinensis), more susceptible to $S$. musiva, replaced NC11396. In a greenhouse, six rooted cuttings of each clone were planted together in each of 30 plastic boxes measuring $56 \times 46 \times 28 \mathrm{~cm}$. Trees were planted in an alternating grid in boxes instead of individual pots so that the two clones could be exposed to the same soil environment. The soil mix was $1: 1 \mathrm{Fa}-$ fard mix \#2 and sandy loam field soil plus $2 \mathrm{~kg} \mathrm{~m}^{-3}$ Osmocote 1414-14 (Sierra Chemical Co., Milpitas, CA). We applied Liquid Iron (containing $0.05 \% \mathrm{Cu}, 3.25 \% \mathrm{Fe}, 0.15 \% \mathrm{Mn}$, and $0.15 \% \mathrm{Zn}$; Fertilome, Bonham, TX) as a foliar spray at planting, and $0.03 \mathrm{~kg}$ $\mathrm{m}^{-3}$ Peter's 20-20-20 (Scott Sierra, Marysville, $\mathrm{OH}$ ) as a soil application both at planting and subsequently once per month. Lighting was the same as in experiment 1.

The watering regimens were the same as in experiment 1 , except that water was applied to boxes instead of to individual containers, and the monitoring scheme for soil moisture was modified. We monitored $\psi_{\mathrm{PD}}$ at low, moderate, and high intensities. Low intensity sampling involved measuring $\psi_{\mathrm{PD}}$ on one leaf of each clone in one well-watered and one less frequently watered box (four leaves). When low intensity sampling revealed a $\psi_{\mathrm{PD}}$ below $-0.5 \mathrm{MPa}$ for any of the leaves, we sampled from three boxes (moderate intensity, 12 leaves). When moderate intensity sampling revealed that the $\psi_{\mathrm{PD}}$ had fallen below $-1.0 \mathrm{MPa}$, we sampled two trees of each clone for every box (high intensity, 120 leaves). All boxes were then watered to field capacity.

Three trees of each clone in every box were inoculated with $S$. musiva isolate 92-49A; the other three of each clone were used as wounded controls (nonwounded controls, which produced no response in experiment 1 , were omitted). The inoculation procedure was the same as described above except that we used the second fully expanded leaf from the shoot apex. Inoculum plugs were removed from plates containing PLDA that had been inoculated 7 days earlier by spreading $10^{6}$ conidia of $S$. musiva suspended in $1 \mathrm{ml}$ of sterile water on the agar surface. Response of trees to the fungus was evaluated and statistically analyzed as described for experiment 1 .

Stem segments were harvested after 75 days, and kept at $4^{\circ} \mathrm{C}$ until we could examine them for signs of the fungus and reisolate from them. We examined each stem segment, including the site of inoculation and resulting canker, under a dissecting microscope for the presence of pycnidia with visible cirrhi. Cirrhi were placed on microscope slides and examined under a compound microscope to confirm the presence of $S$. musiva conidia. A modified procedure of Long (12) was used to reisolate the fungus. We dipped stem segments into $95 \%$ ethanol, flamed them for $5 \mathrm{~s}$, and cut

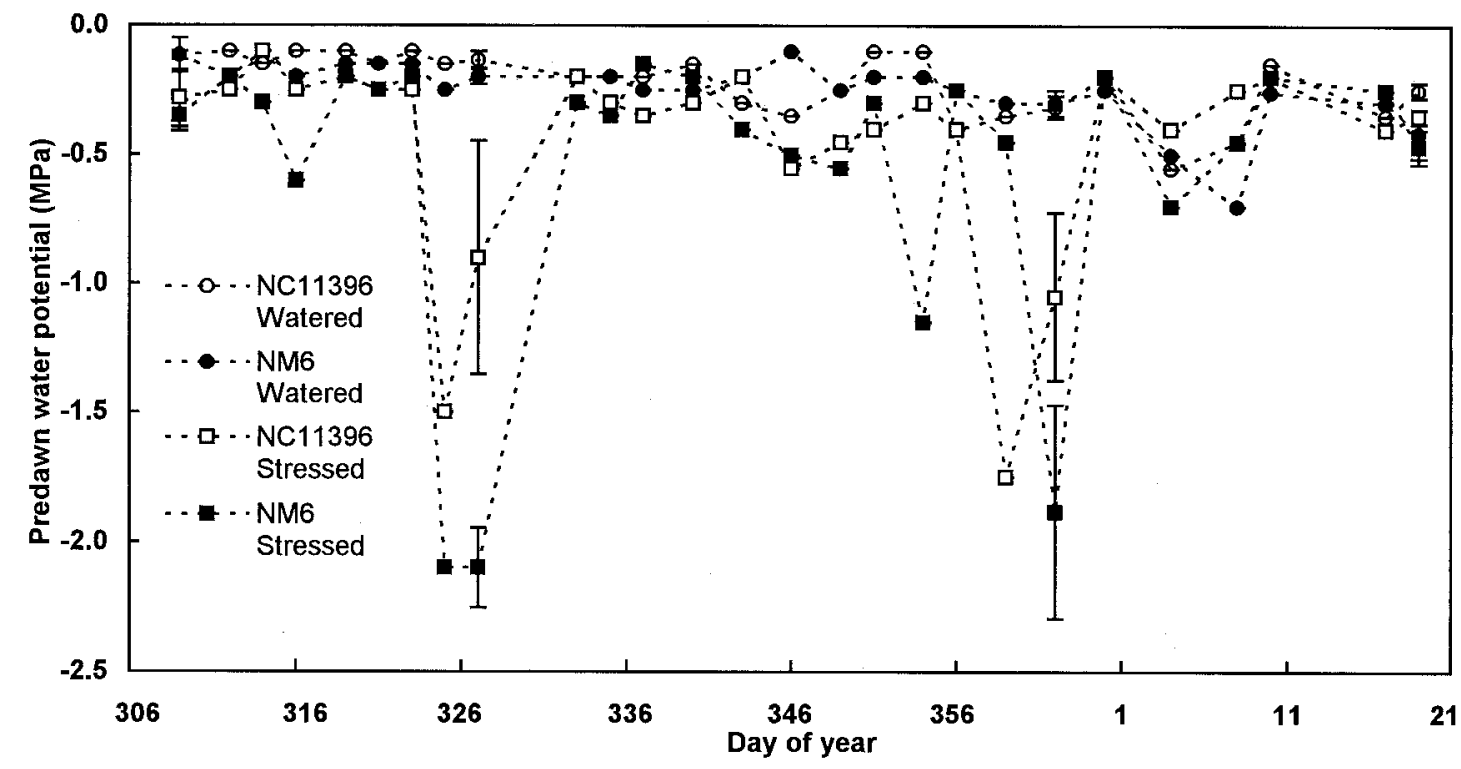

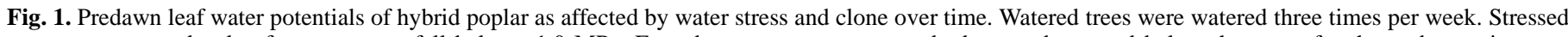

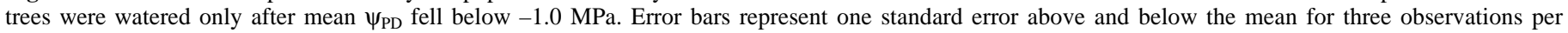
treatment combination. 
5-mm square chips of bark from the inoculation point and from the basal and apical margins of the canker. We also collected three bark chips from our controls: one chip from the site of wounding and two chips from $1 \mathrm{~cm}$ on either side of the wounding site. Each bark chip was placed in a sieve-bottomed crucible and dipped for $2 \mathrm{~s}$ in $95 \%$ ethanol, for $30 \mathrm{~s}$ in a $0.5 \% \mathrm{NaOCl}$ solution, and then for $2 \mathrm{~s}$ in sterile distilled water. We placed the crucibles on a blotting surface to remove excess moisture, and placed the bark chips in slants of $2 \%$ water agar (WA). We subsequently examined these slants for the presence of $S$. musiva spores and $S$. musiva-like mycelium. To confirm that the mycelium was accurately identified, we randomly chose $10 \%$ of the cultures that had $S$. musiva-like mycelia to further attempt identification of the pathogen. This was done by subculturing until conidia were produced or the cultures became overgrown with other organisms and no $S$. musiva-like mycelium was visible. Frequencies of identification among the different treatments were compared by means of $\chi^{2}$ analysis in the FREQ procedure of SAS.

Experiment 2, leaf-disk bioassay. A leaf-disk bioassay was performed three times during the course of experiment 2 . Before dawn on the last morning of each drying cycle (before watering), we removed the second fully expanded leaf from the shoot apex. Before measuring the $\psi_{\mathrm{PD}}$ as described above, we used a cork borer to cut two 15-mm-diameter disks from each leaf for use in a bioassay. Disks were kept in moist chambers on ice until they could be transported to the lab and kept at $4^{\circ} \mathrm{C}$ until they were used the same day.

The leaf-disk bioassay was modified from those of Spiers (29) and Ostry et al. (25). Leaf disks were randomly placed, abaxial surface up, on top of $1 \mathrm{ml}$ of $2 \%$ WA in wells of 24 -well tissue

TABLE 1. Analysis of variance for the effects of clone ${ }^{\mathrm{a}}$ and water stress on canker length and estimated percentage of the stem girdled for control, and $S$. musiva-inoculated ${ }^{\mathrm{b}}$ trees after 80 days

\begin{tabular}{|c|c|c|c|c|c|c|c|c|}
\hline \multirow[b]{2}{*}{ Source } & \multirow[b]{2}{*}{$\mathrm{df}$} & \multicolumn{3}{|c|}{ Control } & \multirow[b]{2}{*}{ df } & \multicolumn{3}{|c|}{ S. musiva-inoculated } \\
\hline & & Type III MS & $F$ & $P$ & & Type III MS & $F$ & $P$ \\
\hline \multicolumn{9}{|c|}{ Canker length } \\
\hline Total & 29 & & & & 58 & & & \\
\hline Stress & 1 & 0.21 & 0.05 & 0.8189 & 1 & 636.89 & 10.24 & 0.0024 \\
\hline $\mathrm{C} \times \mathrm{S}$ & 1 & 2.21 & 0.55 & 0.4644 & 1 & 0.36 & 0.01 & 0.9398 \\
\hline Inoc & & & & & 1 & 1205.16 & 19.37 & 0.0001 \\
\hline Error & 26 & 4.02 & & & 51 & 62.21 & & \\
\hline \multicolumn{9}{|c|}{ Stem girdling (\%) } \\
\hline Total & 29 & & & & 58 & & & \\
\hline Clone & 1 & 318.94 & 8.65 & 0.0068 & 1 & 50.17 & 0.10 & 0.7562 \\
\hline Stress & 1 & 5.95 & 0.16 & 0.6911 & 1 & 1597.45 & 3.10 & 0.0842 \\
\hline $\mathrm{C} \times \mathrm{S}$ & 1 & 50.75 & 1.38 & 0.2513 & 1 & 43.17 & 0.08 & 0.7733 \\
\hline
\end{tabular}

${ }^{\mathrm{a}}$ For each stress and isolate treatment combination, seven NM6 (P. nigra $\times$ P. maximowiczii) and eight NC11396 (P. nigra $\times$ P. beroliniensis $)$ trees were used. Water stress was induced by withholding water from pots until the mean $\psi_{\mathrm{PD}}$ fell below $-1.0 \mathrm{MPa}$. Well-watered trees were watered to field capacity three times per week.

${ }^{\text {b }}$ After removing the fourth fully expanded leaf, we placed a poplar leaf decoction agar plug that was either sterile, or colonized by $S$. musiva isolate 92-49A or 92-49C, over the wound. We performed separate analyses on data from control and inoculated trees, because the variance was much larger for inoculated trees. Nonwounded controls were not included in this analysis because of the extremely low variability, and because any measurable response was due to normal leaf abscission processes and not any experimental treatment.

TABLE 2. Analysis of variance for the effects of clone ${ }^{\mathrm{a}}$ and water stress on canker length and estimated percentage of the stem girdled for control, and $S$. $m u$ siva-inoculated ${ }^{\mathrm{b}}$ trees after 75 days

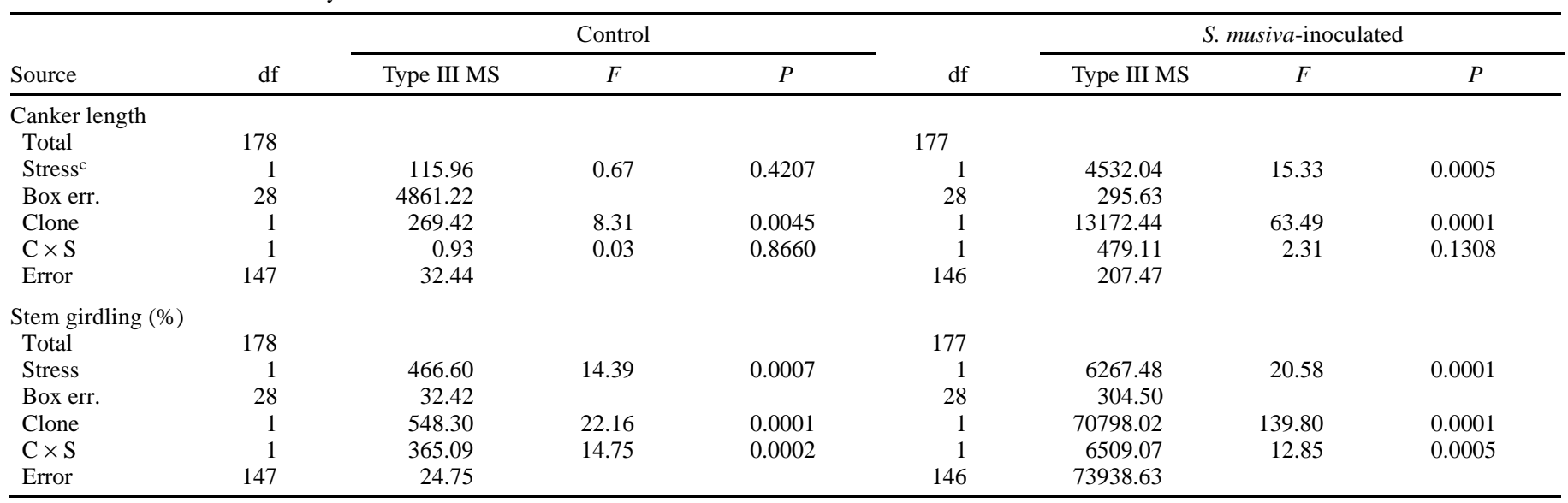

${ }^{a}$ We watered 180 greenwood cuttings each of clones NM6 (P. nigra $\times$ P. maximowiczii) and NE308 (P. nigra var. charkowiensis $\times$ P. berolinensis) either three times per week or after the mean $\psi_{\mathrm{PD}}$ fell below $-1.0 \mathrm{MPa}$.

${ }^{\mathrm{b}}$ After removing the second fully expanded leaf, we placed a poplar leaf decoction agar plug that was either sterile, or colonized by $S$. musiva, over the wound. We performed separate analyses on data from control and inoculated trees, because the variance was much larger for inoculated trees.

${ }^{\mathrm{c}}$ Because watering treatment was applied at the level of box, we used box-to-box variability to test for the effect of stress. 
culture plates. We applied $0.1 \mathrm{ml}$ of sterile water to one randomly selected disk in each pair, and $0.1 \mathrm{ml}$ of a suspension of $10^{4} \mathrm{co}-$ $\mathrm{nidia} / \mathrm{ml}$ to the other. The tissue culture plates containing leaf disks were sealed with Parafilm and incubated at $21^{\circ} \mathrm{C}, 25 \mathrm{~cm}$ below continuous fluorescent lights for 9 weeks. We also inoculated $2 \%$
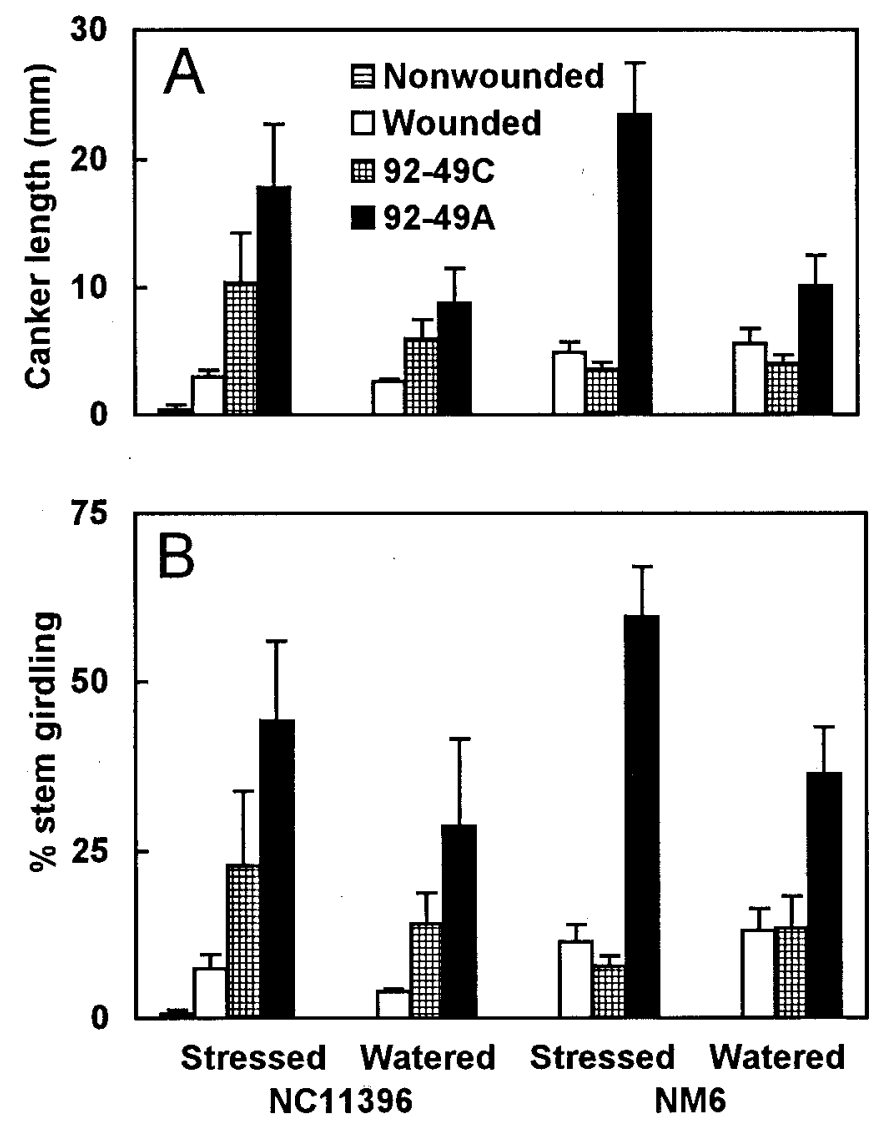

Fig. 2. A, canker length and $\mathbf{B}$, percentage of stem girdling of rooted cuttings of hybrid poplar clones 80 days after inoculation with Septoria musiva. Trees were treated by removing the fourth fully expanded leaf and placing either a sterile poplar leaf decoction agar plug or one colonized by $S$. musiva $92-49 \mathrm{~A}$ or $92-49 \mathrm{C}$ over the wound. For each stress and isolate treatment combination, seven NM6 (Populus nigra $\times$ P. maximowiczii) and eight NC11396 (P. nigra $\times$ P. beroliniensis) trees were used. Error bars represent one standard error above the mean.
WA plates to quantify spore germination. Incubation conditions for spore germination plates were the same as for the leaf disks, except that they were only incubated for $24 \mathrm{~h}$. After $24 \mathrm{~h}$, we determined the percentage of spore germination by examining 100 conidia. Spores were considered to be germinated if the germ tube was one-fourth as long as the conidium.

We measured relative disease severity for each leaf disk at various intervals. Images of each leaf disk were acquired using a Sony 3CCD color video camera (Sony Corp. of America, Montvale, NJ) and a Targa+ frame grabber board (Truevision, Inc., Indianapolis, IN) and saved on an optical disk as JPEG compressed files. Later, Optimas 4.1 (Bioscan, Inc., Redmond, WA) was used to assess the relative severity of disease symptoms for each disk. We wrote a macro for this program that semi-automated the process of distinguishing darkly colored necrotic tissue from healthy green tissue, which resulted in a rapid ( $3 \mathrm{~min} / \mathrm{sample}$ ), accurate, and nondestructive measure of symptom development. The GLM procedure in SAS was used to test the effects of watering regimen (stress), disk treatment (inoculation), and clone. The full ANOVA models for percentage of leaf disk necrosis showed a large difference between control and inoculated treatments. However, the variance for control disks was much smaller than for inoculated disks. Therefore, we performed separate analyses.

TABLE 3. Numbers of poplar trees inoculated ${ }^{a}$ with Septoria musiva showing the presence or absence of conidia 75 days after stem inoculation as affected by clone and water treatment ${ }^{\mathrm{b}}$

\begin{tabular}{|c|c|c|c|}
\hline \multirow[b]{2}{*}{ Water treatment ${ }^{\mathrm{c}}$} & \multirow[b]{2}{*}{ Clone } & \multicolumn{2}{|c|}{ Conidia } \\
\hline & & Absent & Present \\
\hline \multirow[t]{2}{*}{ Well watered } & NE308 & 15 & 30 \\
\hline & NM6 & 41 & 4 \\
\hline \multirow[t]{2}{*}{ Stressed } & NE308 & 20 & 25 \\
\hline & NM6 & 33 & 12 \\
\hline
\end{tabular}

a After removing the second fully expanded leaf from 180 greenwood cuttings each of clones NM6 (P. nigra $\times$ P. maximowiczii) and NE308 ( $P$. nigra var. charkowiensis $\times P$. berolinensis), we placed a colonized poplar leaf decoctoin agar plug over the wound.

${ }^{b}$ Trees were watered either three times per week or after mean $\psi_{\mathrm{PD}}$ fell below $-1.0 \mathrm{MPa}$.

${ }^{c}$ For each water treatment, $\chi^{2}$ analysis indicates lack of independence of clone and presence or absence of spores. For the well-watered treatment $P$ $=0.005$; for stressed $P<0.001 . \chi^{2}$ analysis also shows a significant threeway interaction between watering, clone, and presence or absence of spores $(P=0.017)$.

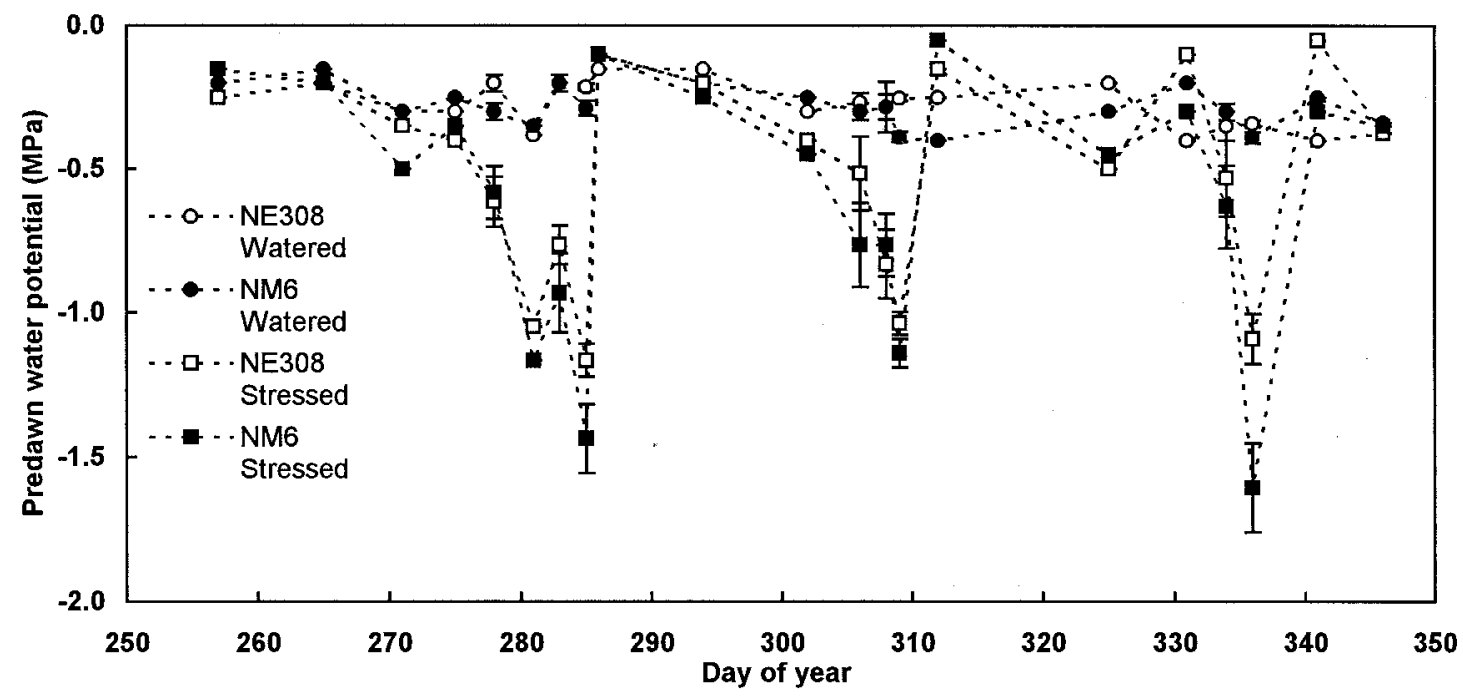

Fig. 3. Predawn leaf water potentials of hybrid poplar as affected by water stress and clone over time. Watered boxes were watered three times per week; stressed boxes were watered only after $\psi_{\mathrm{PD}}$ fell below $-1.0 \mathrm{MPa}$. Error bars represent one standard error above and below the mean for three observations per treatment combination on days of the year 278, 283, 306, 308, and 334; and for 30 observations on days 285, 309, and 336. 


\section{RESULTS}

Experiment 1, stem inoculation. Watering regimen influenced $\psi_{\mathrm{PD}}$ for both clones. Among the four dates when $\psi_{\mathrm{PD}}$ was most intensively measured, well-watered trees had a significantly higher $\psi_{\mathrm{PD}}$ than water-stressed trees on days of year $327(P=$ $0.0005)$ and $362(P=0.0024)$. A clonal difference was also evident. Water-stressed NM6 trees showed significantly more negative mean $\psi_{\mathrm{PD}}$ than NC11396 trees (Fig. 1) on days of year $327(P$ $=0.0077)$ and $362(P=0.0567)$. No significant differences in $\psi_{\mathrm{PD}}$ between watering regimens were detected on days of year 309 and 19 (Fig. 1).

Inoculation treatment (Table 1) affected both canker length (Fig. $2 \mathrm{~A} ; P<0.0001$ ) and estimated girdling percentage (Fig. $2 \mathrm{~B} ; P<$ $0.0001)$. Averaged across all treatments, inoculation with either isolate produced larger cankers than the responses of the wounded controls. Additionally, isolate 92-49A produced larger cankers than $92-49$ C.

Clones interacted differently with different inoculation treatments (Table 1$)$ in terms of both canker length $(P=0.0457)$ and estimated girdling percentage $(P=0.1356)$. In response to isolate 92-49A, clone NM6 produced larger cankers than NC11396. By contrast, when 92-49C was the inoculum, NC11396 developed larger cankers than NM6. For NM6, wounded controls actually produced a slightly greater response than trees inoculated with isolate $92-49 \mathrm{C}$.

When inoculated, water-stressed trees developed larger cankers than well-watered trees, which was indicated by a significant stress $\times$ inoculation interaction for both canker length $(P=$ $0.0006)$ and percent stem girdling $(P=0.0870)$. Mean canker length (Fig. 2A) and percentage of girdle (Fig. 2B) of stems on water-stressed trees of either clone inoculated with isolate 92-49A were greater than those on well-watered trees inoculated with this isolate. The same response occurred for isolate 92-49C on NC11396 only.

Experiment, 2 stem inoculation. The two watering regimens again resulted in significantly different $\psi_{\mathrm{PD}}$ for watered and stressed trees. All moderate and high intensity sampling dates had more negative $\psi_{\mathrm{PD}}$ for nonwatered trees than for well-watered trees (Fig. 3; $P<0.0001$ ). In addition, at the three high intensity sampling dates, we detected differences between clones when water-stressed: NM6 was more water-stressed, with $P$ values of 0.0447, 0.1129, and 0.0045 for the first, second, and third high intensity sampling dates, respectively.

NE308 responded differently than NM6, both when wounded and when inoculated (Table 2). When inoculated, NE308 trees developed larger cankers than NM6 in terms of both canker length (Fig. 4A, $P<0.0001$ ) and stem girdling percentage (Fig. 4B, $P<$ $0.0001)$. For wounded controls, the wound response was larger on NM6 than on NE308 $(P=0.0045$ for canker length, $P<0.0001$ for girdling percentage).

When inoculated, water-stressed trees developed larger cankers (Table 2). This was true for both clones in terms of canker length (Fig. 4A, $P=0.0005$ ). However, this was true only for NM6 in terms of girdling percentage (Fig. 4B). NE308 developed the same amount of girdling regardless of its moisture status (Table $2, \mathrm{C} \times \mathrm{S}$ of ANOVA for stem girdling; $P=0.0005)$.

Upon examining the trees for the presence of $S$. musiva pycnidia and conidia immediately after harvesting, we found significant differences between control and inoculated trees and for the effects of clone and water treatment on inoculated trees. We observed evidence of sporulation on $40 \%$ of the trees that had

TABLE 4. Analysis of variance for the effects of water stress ${ }^{\mathrm{a}}$ and clone on percent necrosis of leaf disks treated with either $S$. musiva or sterile water ${ }^{\mathrm{b}}$

\begin{tabular}{|c|c|c|c|c|c|c|c|c|}
\hline \multirow[b]{2}{*}{ Source } & \multirow[b]{2}{*}{ df } & \multicolumn{3}{|c|}{ Control } & \multirow[b]{2}{*}{ df } & \multicolumn{3}{|c|}{ S. musiva-inoculated } \\
\hline & & Type III MS & $F$ & $P$ & & Type III MS & $F$ & $P$ \\
\hline \multicolumn{9}{|c|}{16 days after inoculation ${ }^{c}$} \\
\hline Total & 119 & & & & 119 & & & \\
\hline Stress & 1 & 12.22 & 1.77 & 0.1936 & 1 & 4835.40 & 4.99 & 0.0337 \\
\hline Box err. & 28 & 6.89 & & & 28 & 969.68 & & \\
\hline Clone & 1 & 2.44 & 0.26 & 0.6095 & 1 & 6785.15 & 12.02 & 0.0008 \\
\hline $\mathrm{C} \times \mathrm{S}$ & 1 & 1.80 & 0.19 & 0.6605 & 1 & 40.11 & 0.07 & 0.7905 \\
\hline Error & 88 & 9.27 & & & 88 & 564.67 & & \\
\hline \multicolumn{9}{|c|}{21 days after inoculation } \\
\hline Total & 119 & & & & 119 & & & \\
\hline Stress & 1 & 1.80 & 0.02 & 0.8895 & 1 & 2086.17 & 2.77 & 0.1074 \\
\hline Box err. & 28 & 91.53 & & & 28 & 754.17 & & \\
\hline Clone & 1 & 339.70 & 3.62 & 0.0603 & 1 & 7115.42 & 12.05 & 0.0008 \\
\hline $\mathrm{C} \times \mathrm{S}$ & 1 & 26.71 & 0.03 & 0.5944 & 1 & 130.42 & 0.22 & 0.6396 \\
\hline Error & 88 & 93.81 & & & 88 & 590.55 & & \\
\hline \multicolumn{9}{|c|}{44 days after inoculation } \\
\hline Total & 119 & & & & 119 & & & \\
\hline Stress & 1 & 477.60 & 6.37 & 0.0175 & 1 & 10502.86 & 9.18 & 0.0052 \\
\hline Box err. & 28 & 74.93 & & & 28 & 1143.79 & & \\
\hline Clone & 1 & 65.42 & 0.67 & 0.4162 & 1 & 4342.95 & 3.00 & 0.0866 \\
\hline $\mathrm{C} \times \mathrm{S}$ & 1 & 48.64 & 0.50 & 0.4830 & 1 & 457.43 & 0.32 & 0.5752 \\
\hline Error & 88 & 98.03 & & & 88 & 1445.67 & & \\
\hline \multicolumn{9}{|c|}{63 days after inoculation } \\
\hline Total & 119 & & & & 119 & & & \\
\hline Stress & 1 & 406.49 & 1.41 & 0.2456 & 1 & 4255.68 & 10.37 & 0.0032 \\
\hline Box err. & 28 & 288.98 & & & 28 & 410.22 & & \\
\hline Clone & 1 & 2421.55 & 7.83 & 0.0063 & 1 & 7100.95 & 18.53 & 0.0001 \\
\hline $\mathrm{C} \times \mathrm{S}$ & 1 & 355.90 & 1.15 & 0.2862 & 1 & 251.14 & 0.66 & 0.4203 \\
\hline Error & 88 & 309.10 & & & 88 & 383.15 & & \\
\hline
\end{tabular}

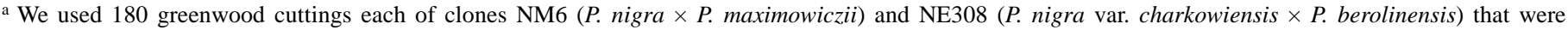

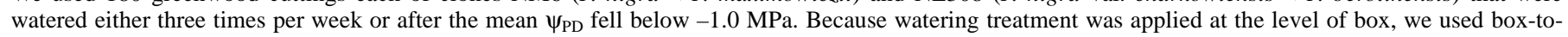
box variability to test for the effect of stress.

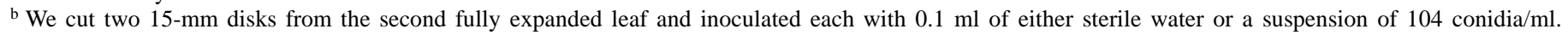
Because the variance was much larger for inoculated disks, separate analyses were performed on data from control and inoculated disks.

c Images acquired 16, 21, 44, and 63 days after inoculation were from disks excised on days of the year 336, 285, 306, and 336, respectively. 
been inoculated, but never on the controls. S. musiva was observed to sporulate on NE308-inoculated stems significantly more frequently than on NM6 trees (Table 3). We observed evidence of sporulation on NM6 three times more frequently when the trees were water-stressed than when they were well-watered. Sporulation was evident on NE308 slightly less often in the stressed condition (25 times) than in the nonstressed condition (30 times).

After incubating surface-sterilized bark chips, we observed significant differences in frequency of recovery of $S$. musiva on control and inoculated trees, but no significant effects of water stress or clone (data not shown). We never observed S. musiva mycelia or spores on chips from control trees. On bark chips from inoculated trees, we observed S. musiva mycelia approximately $29 \%$ of the time. When we observed $S$. musiva mycelia, we also observed conidia approximately $2 \%$ of the time. In 14 randomly chosen tubes containing $S$. musiva mycelia, we were able to induce production of $S$. musiva conidia nine times ( $64 \%$ of the time).

Experiment 2, leaf disk bioassay. Responses of inoculated disks of the two clones were significantly different. Inoculated
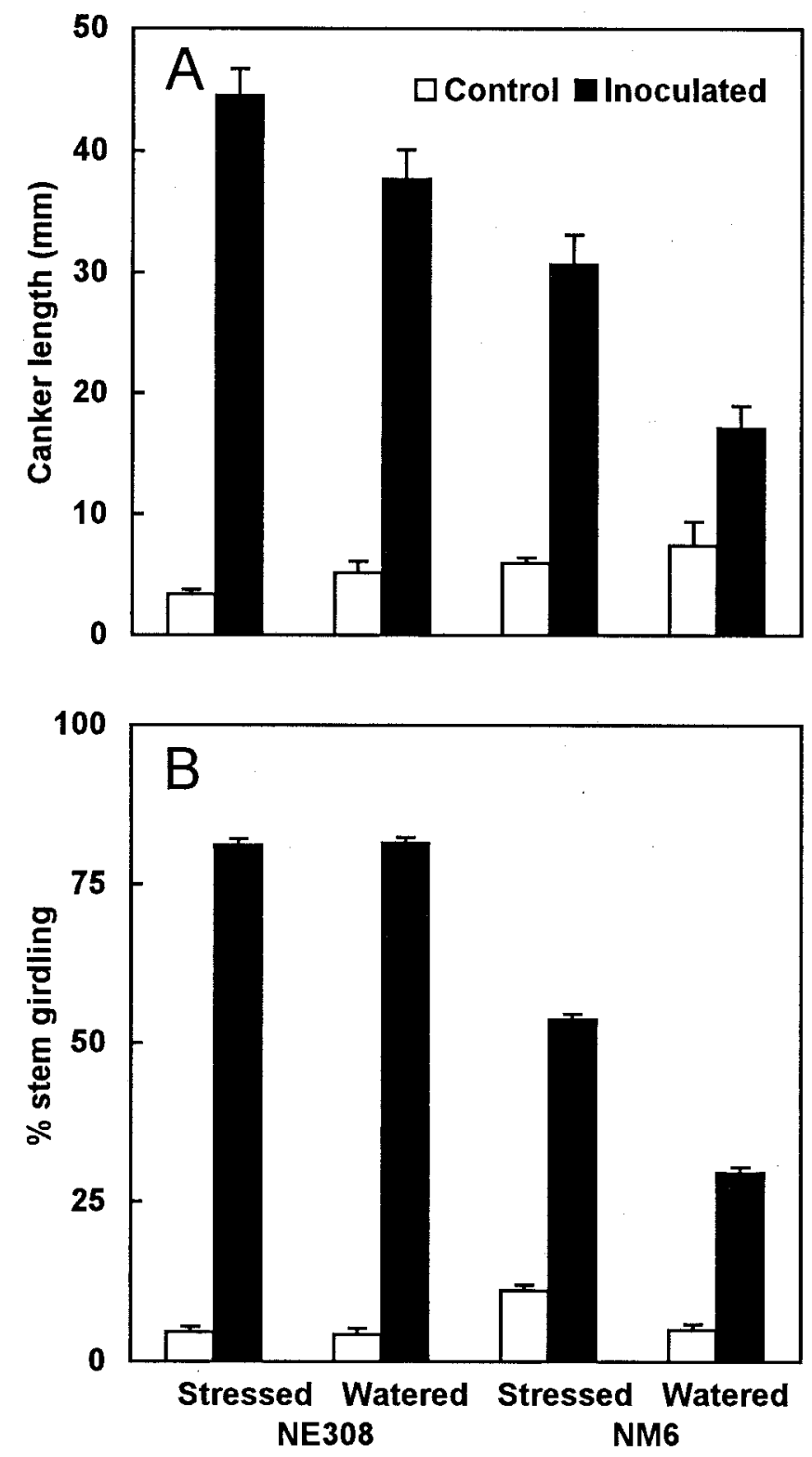

Fig. 4. A, canker length and $\mathbf{B}$, percentage of stem girdling, of rooted cuttings of hybrid poplar clones 75 days after inoculating with Septoria musiva. We removed the second fully expanded leaf and applied either a sterile poplar leaf decoction agar plug or one colonized by $S$. musiva over the wound. Error bars represent one standard error above the mean for 45 observations per treatment combination. leaf disks from NM6 developed more necrosis than those from NE308 (Fig. 5). This was true at all four times of measurement, with $P$ values ranging from 0.0866 to 0.0001 (Table 4 ).

The response of leaf disks was also sensitive to host condition. Disks from well-watered trees developed more necrosis than those from water-stressed trees (Fig. 5). The $P$ values ranged from 0.0052 to 0.0001 for the inoculated disks (Table 4).

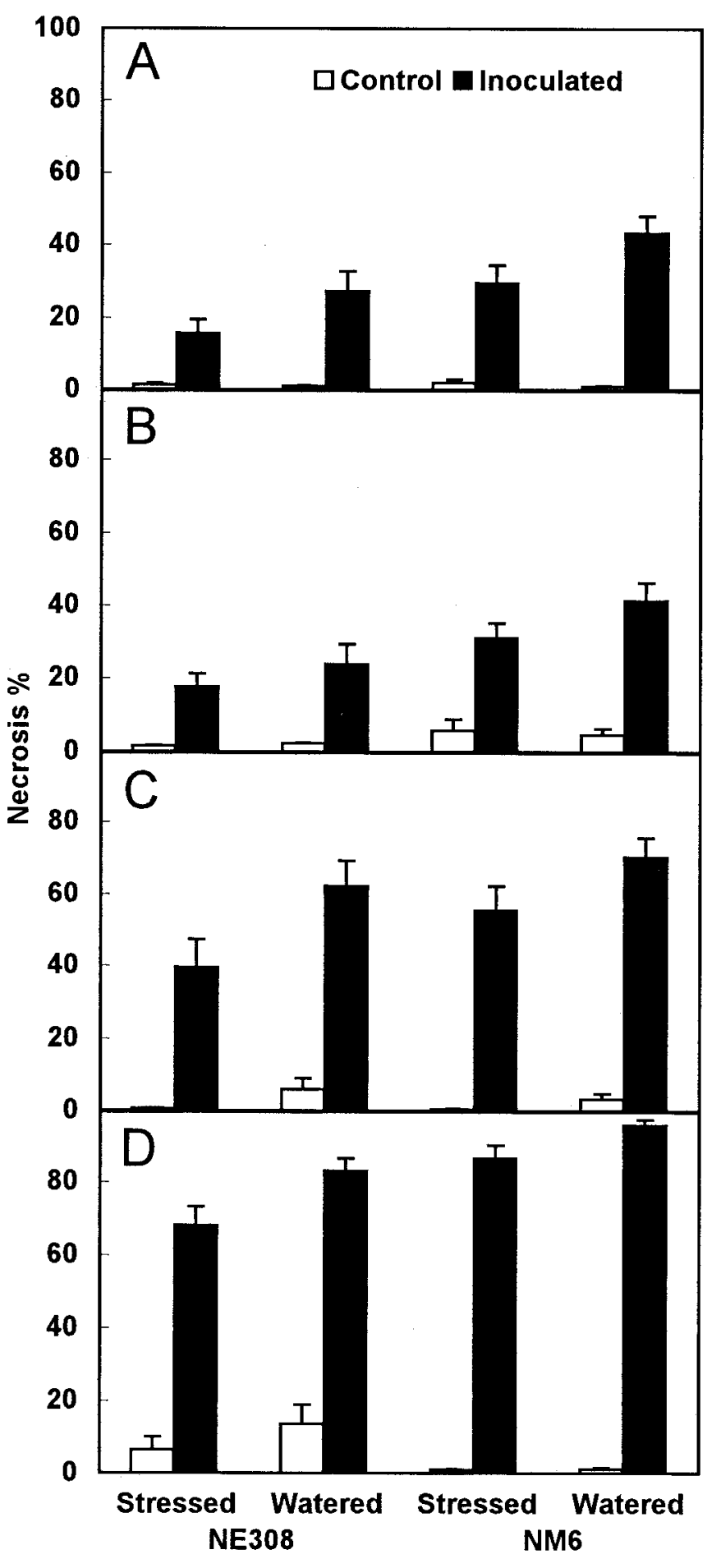

Fig. 5. Mean percentage of necrotic area on poplar leaf disks inoculated with Septoria musiva as affected by preinoculation water treatment and hybrid poplar clone. Leaf disks were excised from the second fully expanded leaf, placed abaxial surface up on $1 \mathrm{ml}$ of $2 \%$ water agar in 24-well tissue culture plates, and treated with $0.1 \mathrm{ml}$ of either sterile water or a suspension of $10^{4}$ conidia/ml. Disks were excised on days of the year A and D, 336; B, 285; and $\mathbf{C}, 306$. Images were captured after $\mathbf{A}, 16 ; \mathbf{B}, 21 ; \mathbf{C}, 44$; and $\mathbf{D}, 63$ days. Error bars represent one standard error above the mean for 30 observations per treatment combination. 


\section{DISCUSSION}

This research establishes that host water stress enhances Septoria canker development in rooted cuttings of hybrid poplar. In previous studies of the interaction between hybrid Populus species and $S$. musiva, environmental factors have been ignored or not controlled. Environmental influences on host condition must be considered in screening for canker resistance and other future research.

Although the inoculation method was artificial, it consistently produced cankers that resembled those attributed to $S$. musiva in the field. While this assay might not indicate how host factors influence the processes of penetration and establishment involved in infection through intact tissue, it did reflect differences in clonal susceptibility and environmental effects. Therefore, it is a tool that may be useful in examining environmental and clonal differences in the responses of hybrid poplar clones to $S$. musiva. The lack of consistency between the results of stem inoculation and of the leaf disk assay, with or without stress, indicates a potential limitation of the excised plant part assay or a danger in extrapolation from the assay to canker susceptibility. There may be very different mechanisms controlling responses of the host to the pathogen in different organs. However, responsiveness of the leaf disk assay to $\psi_{\mathrm{PD}}$ under which the host was grown prior to disk collection suggests that varying environmental conditions could change relative rankings of clones determined by this means. The fact that the response of control disks also was influenced by precollection $\psi_{\mathrm{PD}}$ indicates that the results of the leaf disk assay, to some degree, are influenced by the rate at which leaves become necrotic even in the absence of $S$. musiva.

Much of the focus of research on S. musiva has involved the search for clonal resistance $(11,16,23,24)$. However, disease incidence and severity have varied from site to site $(22,24)$, and it is not clear if this is because of environmental conditions or due to the distribution of the fungus. Ratings of canker incidence and severity for the same trees may also vary over time. Lo et al. (11) found that rankings of clones after 3 years of growth did not always predict rankings after 9 years. These inconsistencies could be due to age-related changes in host susceptibility, environmental factors, or both.

Our results are consistent with the general conclusion that environmental factors strongly influence canker development by fungal pathogens on woody plant hosts. In most cases, water stress leads to increased severity of cankering (27). Lasiodiplodia theobromae caused larger cankers on water-stressed dogwood (Cornus florida) (17). Similar responses have been observed on other angiosperms, including Populus species. Bagga and Smalley (2) demonstrated that Hypoxylon pruinatum induced larger cankers on water-stressed Populus tremuloides. Cuttings of Populus hybrid NE388 showed a similar response to Cytospora chrysosperma (6). Larger cankers may also develop on water-stressed gymnosperms. Examples include Cytospora kunzei on blue spruce (Picea pungens) (28) and Sphaeropsis sapinea on red pine (Pinus resinosa) (8). However, specific exceptions to this generalization must be noted. In field plots, water-stressed cypress (Cupressus sempervirens) trees inoculated with Seridium cardinale developed smaller cankers than well-watered trees (14). Likewise, Jacobi and Riffle (9) observed smaller cankers on water-stressed honey locust (Gleditsia triacanthos) inoculated with Thyronectria austroamericana. Thus, it is necessary to establish the effect of host water stress for each interaction.

Our results also are consistent with previously published work demonstrating enhanced canker development in trees exposed to ozone. Woodbury et al. (34) showed that chronic exposure to ozone significantly increased the incidence and severity of canker caused by S. musiva on Populus hybrid DN34. This suggests the potential for numerous environmental agents having many different mechanisms of effect to induce susceptibility. Alternatively, more general processes that are influenced by a wide range of factors may regulate susceptibility. For example, phytoalexin production (35) and processes involved in the nonspecific woundhealing response (5) are inhibited in metabolically compromised hosts.

Previous studies in diverse plant-pathogen systems have indicated that more extreme water stress might be necessary to stimulate canker development. For instance, to study the effects of water stress on Lasiodiplodia canker of Dogwood, Mullen et al. (17) withheld water until $60 \%$ of the trees in their study showed incipient wilt; and Schoeneweiss (28) studied Cytospora canker of blue spruce in trees with $\psi_{\mathrm{PD}}$ between -2.0 and $-3.0 \mathrm{MPa}$. Bier (4) suggested that there was a threshold level of bark moisture, 69 to $71 \%$, below which $S$. musiva was active in unrooted cuttings of Populus species. In unrooted dormant cuttings of Populus hybrid NE388, Biggs et al. (6) measured $\psi_{\mathrm{PD}}$ to be $-2.7 \mathrm{MPa}$ when bark moisture was $68 \%$ and $-1.9 \mathrm{MPa}$ when bark moisture was $76 \%$. Thus, Bier (4) was probably working with much more severely stressed plants (between -1.9 and $-2.7 \mathrm{MPa}$ ) than those we used. Our results demonstrate that $S$. musiva is responsive to host $\psi_{\mathrm{PD}}$ even at more moderate stresses that routinely occur in the field.

The mechanism of resistance to development of cankers caused by $S$. musiva is unknown. However, the work of Woodbury et al. (34) demonstrated that susceptibility to S. musiva decreased rapidly with the passage of time. We might conclude from this that events in the bark, either soon after wounding or early in the process of pathogen invasion, might be critical to the resistance response. Factors that interfere with this process by either decreasing or delaying wound healing may increase susceptibility. One category of these responses that has been demonstrated to be inhibited by water stress is nonspecific wound healing (6), which involves the production of necrophylactic periderms and nonsuberized impervious tissues (NIT). Necrophylactic periderms are probably initiated within hours after wounding (19) and are formed externally to NIT (7). The development of NIT may be involved in the host response to bark diseases (18). Biggs et al. (7) observed that, in the first week after inoculation, Cytospora chrysosperma easily penetrated lignified zones. Later, a lignified zone in advance of fungal ingress formed impervious qualities, a necrophyllactic periderm formed around this zone, and fungal growth was restricted. Whether these processes are critical to the resistance response of poplars to $S$. musiva, and whether selecting for conditions that allow rapid phylloderm responses will be useful in preventing this disease, might be the subject of future research.

\section{ACKNOWLEDGMENTS}

We thank the USDA (Hatch), the A. J. Riker Fund, and W. Heckrodt for financial support. We thank B. Yandell for statistical advice, J. Blodgett and S. Heuchelin for presubmission reviews, and two anonymous reviewers and $\mathrm{K}$. Johnson for their helpful suggestions. We also thank M. Guthmiller, D. Smith, R. Spear, L. Covert, and S. Birren for technical assistance.

\section{LITERATURE CITED}

1. Abebe, G., and Hart, J. H. 1990. The relationship of site factors to the incidence of Cytospora and Septoria cankers and poplar and willow borer in hybrid poplar plantations. U.S. Dep. Agric. For. Serv. Gen. Tech. Rep. NC-140.

2. Bagga, D. K., and Smalley, E. B. 1969. Factors affecting canker development on Populus tremuloides artificially inoculated with Hypoxylon pruinatum. Can. J. Bot. 47:907-914.

3. Bier, J. E. 1939. Septoria canker of introduced and native hybrid poplars. Can. J. For. Res. 17:195-204.

4. Bier, J. E. 1961. The relation of bark moisture to the development of canker diseases caused by native, facultative parasites VI. Pathogenicity studies of Hypoxylon pruinatum (Klotzsch) cke., and Septoria musiva Pk. on species of Acer, Populus and Salix. Can. J. Bot. 39:1555-1561. 
5. Biggs, A. R. 1992. Responses of gymnosperm bark tissues to fungal infections. Pages 62-74 in: Defense Mechanisms of Woody Plants Against Fungi. R. A. Blanchette and A. R. Biggs, eds. Springer-Verlag Co., New York.

6. Biggs, A. R., Davis, D. D., and Merrill, W. 1983. Cutting development and restriction of wound-associated infection in Populus. Can. J. Plant Pathol. 5:269-272.

7. Biggs, A. R., Merrill, W., and Davis, D. D. 1984. Discussion: Response of bark tissues to injury and infection. Can. J. For. Res. 14:351-356.

8. Blodgett, J. T. 1996. The effects of host water stress on disease development by different Sphaeropsis sapinea morphotypes. Ph.D. thesis. University of Wisconsin-Madison, Madison.

9. Jacobi, W. R., and Riffle, J. W. 1989. Effects of water stress on Thyronectria canker of honeylocusts. Phytopathology 79:1333-1337.

10. Krupinsky, J. M. 1989. Variability in Septoria musiva in aggressiveness. Phytopathology 79:413-416.

11. Lo, M. H., Abrahamson, L. P., White, E. H., and Manion, P. D. 1995. Early measures of basal area and canker disease predict growth potential of some hybrid poplar clones. Can. J. For. Res. 25:1113-1118.

12. Long, R. 1982. Etiology, symptomology, epidemiology, and disease cycle of Septoria canker in a Populus hybrid plantation. M.S. thesis. The Pennsylvania State University, State College.

13. Luley, C. J., Tiffany, L. H., and McNabb, H. S., Jr. 1987. In vitro production of Mycosphaerella populorum ascomata. Mycologia 79:654658.

14. Madar, Z., Solel, Z., and Kimchi, M. 1989. Effects of water stress in cypress on the development of cankers caused by Diplodia pinea $\mathrm{f}$. $\mathrm{sp}$. cupressi and Seridium cardinale. Plant Dis. 73:484-486.

15. McNabb, H. S., Jr., Ostry, M. E., Sonnelitter, R. S., and Gerstenberger, P. E. 1982. The effect and possible integrated management of Septoria musiva in intensive, short-rotation culture of Populus in the North Central States. Pages 51-58 in: Proc. North Am. Poplar Council Mtg., Rhinelander, WI. J. Zavitkovski and E. A. Hansen, eds. Division of Extension, Kansas State University, Manhattan.

16. Moore, L. M., and Wilson, L. F. 1983. Recent advances in research of some pest problems of hybrid Populus in Michigan and Wisconsin. U. S. Dep. Agric. For. Serv. Gen. Tech. Rep. NC-91.

17. Mullen, J. M., Gilliam, C. H., Hagan, A. K., and Morgan-Jones, G. 1991. Canker of dogwood caused by Lasiodiplodia theobromae, a disease influenced by drought stress or cultivar selection. Plant Dis. 75:886-889.

18. Mullick, D. B. 1975. A new tissue essential to necrophylactic periderm formation in the bark of four conifers (Studies of periderm. VI.). Can. J. Bot. 53:2443-2457.

19. Mullick, D. B. 1977. The nonspecific nature of defense in bark and wood during wounding, insect, and pathogen attack. Recent Adv. Phyto- chem. 11:395-441.

20. Niyo, K. A., McNabb, H. S., and Tiffany, L. H. 1986. Ultrastructure of the ascocarps, asci, and ascospores of Mycosphaerella populorum. Mycologia 78:202-212.

21. Ostry, M. E. 1987. Biology of Septoria musiva and Marssonina brunnea in hybrid Populus plantations and control of Septoria canker in nurseries. Eur. J. For. Pathol. 17:158-165.

22. Ostry, M. E., and McNabb, H. S., Jr. 1983. Diseases of intensively cultured hybrid poplars: A summary of recent research in the north central region. Pages 102-109 in: U.S. Dep. Agric. For. Serv. Gen. Tech. Rep. NC-91.

23. Ostry, M. E., and McNabb, H. S., Jr. 1985. Susceptibility of Populus species and hybrids to disease in the north central United States. Plant Dis. 69:755-757.

24. Ostry, M. E., and McNabb, H. S., Jr. 1986. Populus species and hybrid clones resistant to Melampsora, Marssonina, and Septoria. U.S. Dep. Agric. For. Serv. Gen. Tech. Rep. NC-272.

25. Ostry, M. E., McRoberts, R. E., Ward, K. T., and Resendez, R. 1988. Screening hybrid poplars in vitro for resistance to leaf spot caused by Septoria musiva. Plant Dis. 72:497-499.

26. Phelps, J. E. 1983. Biomass from intensively cultured plantations as an energy, chemical, and nutritional feedstock. U.S. Dep. Agric. For. Serv. Gen. Tech. Rep. NC-91.

27. Schoeneweiss, D. F. 1975. Predisposition, stress, and plant disease. Annu. Rev. Phytopathol. 13:193-211.

28. Schoeneweiss, D. F. 1983. Drought predisposition to Cytospora canker in blue spruce. Plant Dis. 67:383-358.

29. Spiers, A. G. 1978. An agar leaf-disc technique for screening poplars for resistance to Marssonina. Plant. Dis. Rep. 62:144-147.

30. Strobl, S., and Fraser, K. 1989. Incidence of Septoria canker of hybrid poplars in eastern Ontario. Can. Plant Dis. Surv. 69:109-112.

31. Teterevnikova-Babayan, D. N. 1976. A critical survey of Septoria species parasitizing Salicaceae II. Septoria species on poplar. (In Russian.) Biol. Zh. Arm. 29:53-61.

32. Thompson, G. E. 1941. Leaf-spot diseases of poplars caused by Septoria musiva and S. populicola. Phytopathology 31:241-254.

33. Waterman, A. M. 1946. Canker of hybrid poplar clones in the United States caused by Septoria musiva. Phytopathology 36:148-156.

34. Woodbury, P. B., Laurence, J. A., and Hudler, G. W. 1994. Chronic ozone exposure increases the susceptibility of hybrid Populus to disease caused by Septoria musiva. Environ. Pollut. 86:109-114.

35. Yamada, T. 1992. Biochemistry of gymnosperm xylem responses to fungal invasion. Pages 147-164 in: Defense Mechanisms of Woody Plants Against Fungi. R. A. Blanchette and A. R. Biggs, eds. SpringerVerlag Co., New York. 